\title{
DISCOVERY OF CUSTOMER SATISFACTION DIMENSION FROM TWEETS USING LATENT DIRICHLET ALLOCATION
}

\author{
Iqbal Hadiyan, Achmad Nizar Hidayanto and Satrio Baskoro Yudhoatmojo \\ Faculty of Computer Science, Universitas Indonesia \\ Kampus UI, Depok, 16424, Jawa Barat, Indonesia
}

\begin{abstract}
Customer satisfaction of a service or product is reflected in the customer's attitude towards the service or product once the customer perceived or used the service or product. Customer satisfaction has many dimensions, and previous studies have identified and used those many dimensions to measure the customer satisfaction of a certain service or product. In this study, we explore the use of text mining techniques of modeling topic as a way of discovering customer satisfaction dimensions, and we used tweets data from Twitter as our dataset. These are our contributions. We believed that this approach had not been used for discovering customer satisfaction dimensions. We used Latent Dirichlet Allocation for the topic modeling, and perplexity model and topic coherence are used for optimizing the number of topics. We would then choose representative words for each topic formed using Latent Dirichlet Allocation. The name of the topic is added by analyzing the logical relationships between the representative words and find the semantic meaning of the representative words in the context of the original tweets. These are done manually by the authors. Once the labels have been identified, we associate the labels to the original tweets. The identified topics in our study become customer satisfaction dimensions. The last task in our study is comparing the identified dimensions with dimensions in previous studies. In this task, we needed to broaden the definition of dimensions from previous studies. The result shows our identified dimensions are fitted with the dimensions from previous studies. The main differences are the naming of the dimensions and the granularity of the dimensions. Our identified dimensions have finer granularity than previous studies. Our study enables the decision maker to be informed with the current dimensions, which are mattered by the customer in using the organization's services or products. Once the tweets are labeled to the identified topic names, we can sort the topics having the most documents. This result shows important issues which are discussed by the customers.
\end{abstract}

\section{KEYWORDS}

Customer Satisfaction Dimensions, Latent Dirichlet Allocation, Twitter, Social Media, Text Mining

\section{INTRODUCTION}

Social media holds a plethora of people opinions about various things. Social media detaches physical boundaries and gaps, which means people from various places, backgrounds, and beliefs can meet and communicate. Companies use social media as a platform for marketing their products and services. This way is more effective in spreading their products and services updates and also allows the customer to interact with the company intensively. Companies can review and give feedback to customer's comments or questions on social media. Thus, social media is a great platform to obtain information about the quality of the product or the performance of the service.

Studies about dimensions of customer satisfaction have been done by many researchers. They identified several dimensions and used the dimensions to measure the customer satisfaction of a product or a service. We have not found a study that customer satisfaction from social media by organically (or clustered) the data to form common topics which represent the dimension of customer satisfaction. This study is important in a sense that customer satisfaction dimensions are not concepts which are set in stone while rather, it is a dynamic concept that may expand or condense depending time and context at hand. 
This study aims to discovery dimensions of customer satisfaction from social media post. We used Twitter as the social media and PT Indosat Tbk. as the company for our case study. We gathered tweets about PT Indosat Tbk. with the aim to clustered discussion topics in which these clusters would resemble dimensions of customer satisfaction. Our rationale is that social media users tend to give an opinion about the product or service they use through the social media platform. Thus, we assume that PT Indosat Tbk. customers would also give their opinion about PT Indosat Tbk. services in social media. The research questions of this study are: (1) "What are the dimensions of customer satisfaction found by analyzing social media post?", and (2) "Do the dimensions found resembles the dimensions previously studied or used in other researches?".

This paper is organized as follows. Section 2 describes the related works of this study. Section 3 describes the research methodology of this study. Section 4 describes the process of discovering the dimensions and comparison between the dimensions found with previous studies. Section 5 concludes our study.

\section{RELATED WORKS}

Customer satisfaction is the customer's view or attitude that his/her expectation of the product or service has been fulfilled or surpassed [Gerson, R. F., 1993] [ Mowen, J., C., and Minor, M., 1997] [ Kotler, P., T., and Amstrong, G., 2017][Kotler, P., 2009][Buttle, F., 2009]. The view or attitude can be positive or negative. The telecommunication industry is one of the growing industries in the past decades. The competition amongst player in this industry has intensified. Companies must increase their customer satisfaction so that in return, the customer loyalty rate is also increased.

Several studies have focused on customer satisfaction in telecommunication services. The following describes the result of our reviews. A study done by [Olatokun, W. M., and Nwonne, S. A., 2012] shows that service quality is a significant factor for customer to choose a mobile service provider. Moreover, [Olatokun, W. M., and Ojo, F. O., 2014] identified and validate five dimensions of service quality: reliability, responsiveness, assurance, empathy, and tangibility. Reliability and tangibility do not significantly influence customer satisfaction, while others have a positive and significant influence on service quality.

An evaluation of the effect of service quality and customer satisfaction on cellular phone service in Greece was done by [Santouridis, I., and Trivellas, P., 2010]. According to their study, service quality is the main predictor for customer satisfaction and customer loyalty [Santouridis, I., and Trivellas, P., 2010]. They used six dimensions of service quality: customer support, price structure, billing system, network quality, value added, and mobile device. Customer support is the only dimension which significantly influences customer satisfaction and customer loyalty, while price structure, billing system, and network quality show a positive influence on them. The value added and mobile device dimensions show no significant influence on customer satisfaction and customer loyalty.

A study by [Wang, Y., and Lo, H.-P., 2002] is based on the service quality model of China's telecommunication service. The model is a modified version of SERVQUAL model. The modification is based on the result of group discussion and opinions from experts to represent specific characteristics of the telecommunication industry and a unique culture in China. There are six service qualities used: tangibles, reliability, responsiveness, assurance, empathy, and network quality.

[Aydin, S., and Ozer, G., 2005] did a study about the history of customer loyalty in the Turkish mobile telecommunication market. They studied the relationship between customer loyalty and service quality, the perception of cost change, trust, and company image. The dimensions used in the study are service quality, trust, company image, and cost change.

In 2003, [Athanassopoulos, A. D., and Iliakopoulos, A., 2003]. A formulated a function of customer satisfaction in telecommunication industry using transaction points between the telecommunication operators and their customers as the foundation of the analysis. The dimensions of customer satisfaction formulated in this study consist of billing, product quality, branch services, company image, the establishment of new services, and troubleshooting problems. 
[Khatibi, A. A., Ismail, H., and Thyagarajan, V., 2002] looked into what drives the customer to become loyal in using telecommunication services. There are three stages in the study. The first stage identified contributing factors for the service quality factor. The second stage used the regression analysis to identify the relationship between service quality element and customer satisfaction. The third stage is the analysis of the relationship between customer loyalty and customer satisfaction. There are 16 factors of service quality, which are grouped into four groups. The first group is competency/capability, which consists of the relationship between sales personnel and marketing material. The relationship has a direct influence on the customer's decision to buy. The second group is assurance, which consists of skills, employee knowledge and courtesy, the employee ability to deliver trust to the customer, and the trust amongst customer. The third group is tangibility, which consists of physical (tangible) services. The fourth group is reliability, which consists of the ability to deliver reliable and accurate services as planned. Table 1 shows customer satisfaction dimensions of previous studies.

Table 1. Customer satisfaction dimensions of previous studies

\begin{tabular}{|c|c|c|c|c|c|c|}
\hline References & $\begin{array}{l}\text { Olatokun, W. } \\
\text { M., and } \\
\text { Nwonne, S. } \\
\text { A., } 2012\end{array}$ & $\begin{array}{c}\text { Santouridis, I., } \\
\text { and Trivellas, } \\
\text { P., } 2010\end{array}$ & $\begin{array}{l}\text { Wang, Y., } \\
\text { and Lo, } \\
\text { H.-P., 2002 }\end{array}$ & $\begin{array}{l}\text { Aydin, S., } \\
\text { and Ozer, G., } \\
2005\end{array}$ & $\begin{array}{l}\text { Athanassopoulos, } \\
\text { A. D., and } \\
\text { Iliakopoulos, A., } \\
2003\end{array}$ & $\begin{array}{c}\text { Khatibi, A. A., } \\
\text { Ismail, H., and } \\
\text { Thyagarajan, V., } \\
2002\end{array}$ \\
\hline \multirow{14}{*}{ 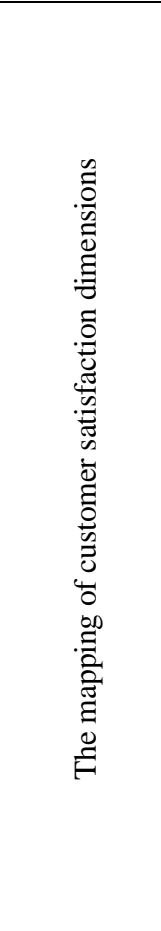 } & \multirow{6}{*}{$\begin{array}{l}\text { Service } \\
\text { Quality }\end{array}$} & $\begin{array}{l}\text { Network } \\
\text { Quality }\end{array}$ & $\begin{array}{l}\text { Network } \\
\text { Quality }\end{array}$ & $\begin{array}{l}\text { Service } \\
\text { Quality }\end{array}$ & & \\
\hline & & & Tangibles & & & Tangibility \\
\hline & & & Reliability & & & Reliability \\
\hline & & & $\begin{array}{l}\text { Responsivene } \\
\text { ss }\end{array}$ & $\begin{array}{l}\text { Customer } \\
\text { Support }\end{array}$ & Branch Service & \\
\hline & & & Assurance & Trust & $\begin{array}{l}\text { Troubleshooting } \\
\text { Problems }\end{array}$ & Assurance \\
\hline & & & Empathy & & & \\
\hline & & & & & Product Quality & \\
\hline & & & & & & $\begin{array}{l}\text { Competency/ } \\
\text { Capability }\end{array}$ \\
\hline & $\begin{array}{ll}\text { Call } & \text { Rate } \\
\text { (Price) } & \end{array}$ & Price Structure & & Cost Change & & \\
\hline & $\begin{array}{l}\text { Service/ } \\
\text { Product } \\
\text { Availability }\end{array}$ & & & & & \\
\hline & Promotion & Value Added & & & $\begin{array}{l}\text { Provision of New } \\
\text { Service }\end{array}$ & \\
\hline & Brand Image & & & $\begin{array}{l}\text { Company } \\
\text { Image }\end{array}$ & Company Image & \\
\hline & & Billing System & & & Billing System & \\
\hline & & Mobile Device & & & & \\
\hline
\end{tabular}

\section{RESEARCH METHODOLOGY}

There are three major steps in our study. The first one is the data collection. We used the Twitter API to crawl through Twitter to collect the data. The keyword "Indosat" is used as a base for crawling the data.

The second step is the data pre-processing. There are three tasks in this step: (1) data pre-processing, (2) case transformation, and (3) pattern discovery. These three tasks used text mining techniques. The data pre-processing starts from removing data duplication that is walking through each tweet to find any duplicated tweets. If any, remove them from the data set. Next, we tokenized the tweets. Tokenization decomposed the tweet into token words. The decomposition is based on space between words and punctuation. After the tweets are tokenized, we performed the case folding process where we transform all letter cases into lower case letters. Lastly, we performed the part-of-speech (POS) tagging, where we labeled 
each part of a sentence. We used Hidden Markov Model (HMM) to label the words with a label such as noun, adjectives, etc.

The second task is case transformation, which consists of two sub-tasks: (1) stop word removal, and (2) stemming. Stop words are common words which largely occur in each tweet. The removal would enable us to obtain the semantic words of each tweet. Stemming is a process of transforming each word into its root form. The third task is pattern discovery, which gives the output a set of semantic words of each tweet known as bag-of-words.

The third major step is topic modeling or dimension modeling. The first task is to use Latent Dirichlet Allocation (LDA) to cluster words into a group of words which represent the topics. The second task is labeling the group of words into topics/dimensions. The third task is to associate the name of topic/dimension into the original tweet corpus. This is labeling the original tweet corpus with topic/dimension identified from the previous task.

\section{ANALYSIS AND RESULT}

In this section, we describe the analysis of our study and its result.

\subsection{The Dataset}

The collected tweets are tweets about services provided by PT Indosat Tbk. The initial data collected by crawling into Twitter is 101,532 tweets. Following the data pre-processing step, the data is cleaned up, and the result is decreased into only 44,586 tweets.

\subsection{Corpus Representation}

The tweets, or call them corpus, are transformed into bag-of-words. The bag-of-words model represents each corpus in an array where each array contains tokenized words. Each distinct word from the whole corpus is associated with an ID and added into a dictionary. A new corpus is introduced in the form of a set of tuples in an array for each document S $[\mathrm{A} 1, \ldots, \mathrm{An}]$. A0i is an ID of a word, and A1i is the frequency of that word.

\subsection{Topic Modeling using LDA}

It is assumed a priori that the corpus consists of a combination of topics/dimensions. It is because we collected data about the services of PT Indosat Tbk. using the keyword "Indosat" where we may have collected various kind of tweets containing that keyword. There are three tasks in modeling the topic/dimension: (1) optimizing the number of topics/dimensions, (2) identifying representative words using LDA, and (3) naming the topic/dimension based on representative words.

\subsubsection{Optimizing the Number of Topics}

We used the perplexity model and topic coherence to optimize the number of topics in our corpus. Gibbs sampling algorithm in the LDA model is used by iterating through the corpus until the likelihood model is optimal and does not change or known as the burn-in period. The process of optimizing the number of topics is done by building several LDA model with different values of topic $\mathrm{k}$ and choose the one with high coherence score. Choosing the $\mathrm{k}$ ends the growth of topic coherency, which provides important topics that are easy to interpret. If we chose a higher coherence score allows us to have detailed sub-topics, but the representative words are repeated/duplicated in every topic. Thus, choosing the optimal coherence score is the key to obtain representative words that are easy to interpret and less repetition/duplication of representative words in every topic. Table 2 shows the coherence score of the tested number of topics. 
Table 2. The coherence score of the tested number of topics

\begin{tabular}{cc}
\hline Number of Topics & Coherence Score \\
\hline 2 & 0.3518 \\
8 & 0.422 \\
14 & 0.44 \\
20 & 0.478 \\
26 & 0.4778 \\
32 & 0.4298 \\
38 & 0.4309 \\
\hline
\end{tabular}

As shown in Table 2, there is a decline of coherence score after 26. Thus, there is a possibility of the optimal number of topics between 26 and 32. We measured the perplexity and topic coherence between these two and found that 30 is the optimal number of topics by having 0.5238 as the coherence score.

\subsubsection{Identifying Representative Words}

We used LDA to identify representative words. For the 30 topics chosen from the previous task, there are five representative words. The list of representative words for each topic can be seen in Table 3 .

Table 3. Representative words for each topic

\begin{tabular}{|c|c|c|c|}
\hline Topic & Representative Words & Named Topic & Number of Corpus \\
\hline Topic 1 & package, matrix, number, card, quota & Subscription & 1223 \\
\hline Topic 2 & phone credit, bonus, $4 \mathrm{~g}$, upgrade, number & Bonus & 282 \\
\hline Topic 3 & community, check, number, community, id & Community & 1071 \\
\hline Topic 4 & iflix, number, pop, quota, collect & Content and Validity & 55 \\
\hline Topic 5 & bts, sweet, milk, business, professional & Corporate Communication & 17 \\
\hline Topic 6 & point, phone credit, content, number, package & Customer Loyalty & 108 \\
\hline Topic 7 & package, $4 \mathrm{~g}$, quota, internet, data & Data Services & 9064 \\
\hline Topic 8 & handphone, kiosk, bundling, package, $\max$ & Device Bundling & 21 \\
\hline Topic 9 & iflix, quota, dompetku, package, number & Digital Services & 446 \\
\hline Topic 10 & phone credit, legend, patagihan, mobile, $100 \mathrm{k}$ & Finance Function & 1 \\
\hline Topic 11 & service, active, data, center, local & Indosat & 2 \\
\hline Topic 12 & gives, receive, number, package, kiosk & Customer Interaction & 5232 \\
\hline Topic 13 & $4 \mathrm{~g}$, signal, network, handphone, internet & Signal Strength & 3750 \\
\hline Topic 14 & retrieve, card, mtronik, email, check & Partnership & 8 \\
\hline Topic 15 & package, matrix, number, card, tariff & Configuration & 158 \\
\hline Topic 16 & matrix, im 3 , freedom, mentari, product & Quiz & 3497 \\
\hline Topic 17 & bills, email, matrix, name, month & Billing Sheets & 163 \\
\hline Topic 18 & profile, mention, stalking, admin, indosat & Mention & 1 \\
\hline Topic 19 & message, yesterday, oot (out of topic), reply, send & Message & 1 \\
\hline Topic 20 & dompetku, balance, PIN, promo, transaction & Mobile Commerce & 314 \\
\hline Topic 21 & package, phone credit, number, $4 \mathrm{~g}$, check & Multi Tweet & 6635 \\
\hline Topic 22 & chelseaindo, ciscgoestolondon, chelsea, city, man & Out of Topic & 3587 \\
\hline Topic 23 & matrix, package, card, number, date & Basic Plan & 47 \\
\hline Topic 24 & telephone, number, phone credit, calls, package & Calls & 722 \\
\hline Topic 25 & pay, bills, ATM, matrix, cimb & Payment & 32 \\
\hline Topic 26 & PUK, code, name, mother, PIN & Customer Profile & 1776 \\
\hline Topic 27 & $32000 a n$, coin, line, amount, refund & Refund & 1 \\
\hline Topic 28 & phone credit, date, content, hour, success & SIM card & 4687 \\
\hline Topic 29 & SMS, indosat, number, handphone, fraud & SMS & 758 \\
\hline Topic 30 & based, internet, super, volume, multi & Twitter & 2 \\
\hline
\end{tabular}

\subsubsection{Naming the Topic/Dimension based on Representative Words}

The resulting representative words from the LDA model show distribution of words of certain topics in which the names of the topics are unknown at this moment. This task has a purpose of naming these topics manually based on the logical relationship between the representative words in each topic and randomly sampled the original corpus to derive the semantic meaning of the words. Amongst the 30 topics/dimensions, 
there is one topic/dimension which the label cannot be determined. It cannot be determined because the representative words are too random. Thus, it is difficult to find the logical relationship between the words. This topic/dimension is labeled as "Out of Topic" (OOT), and further sampling to the original corpus showed that the corpus with this label contains advertisements which are not related to PT Indosat Tbk. but they mentioned or created a hashtag using the word "Indosat." The result of naming the topic/dimension is shown in Table 3 in the third column.

\subsubsection{Associating the Topic/Dimension to Corpus}

The process of associating the topic/dimension to the corpus is done by looking at the probability of the topic in each corpus. Each corpus may contain more than one topic; thus, we need a threshold value for the probability value of the topic. The threshold is measured by averaging the probability of the topic from the whole corpus.

We iterated the whole corpus against the representative words for each topic/dimension which would give us the result of the probability of that corpus belong to certain topics/dimensions. The number of corpora associated with the identified topics/dimension according to the representative words can be seen in Table 3 on the fourth column. Data Services topic has the largest number of the corpus.

From Table 3, there 18 topics/dimensions which have a number of corpora more than 100 corpora. We assumed 100 corpus and above are large enough to conclude these topics/dimensions to be hot topics/dimensions. Next, we compared our identified customer satisfaction dimensions with the ones identified by previous studies done by Olatokun and Nwonne (2012), Santouridis. I and Trivellas. P (2010), Wang. Y, and Lo. H (2002), Aydin. S and Ozer. G (2005), Athanassopoulos. A and Iliakopoulos. A (2003), and Khatibi. A, Ismail. H, and Thyagarajan. V (2002). We broaden the definition of previous studies' dimensions so that our identified dimensions can be classified into the previous studies' dimensions. The mapping result can be seen in Table 4 .

Table 4. The number of corpus per-topic/dimension according to its representative words

\begin{tabular}{ll}
\hline Identified Topic/Dimension of Our Study & Dimension from Previous Studies \\
\hline Customer Interaction & Responsiveness, Customer Support, Branch Service \\
Signal Strength & Network Quality \\
Partnership & Competency \\
Configuration & Reliability \\
Quiz & Promotion/ Value Added/ Provision of New Service, \\
& Empathy \\
Billing Sheets & Billing System \\
Mention & Responsiveness, Customer Support, Branch Service \\
Message & Responsiveness, Customer Support, Branch Service \\
Mobile Commerce & Product Quality, Product Service/ Product Availability \\
Multi tweet & Responsiveness, Customer Support, Branch Service \\
Indosat & Brand Image \\
Basic Plan & Product Quality, Product Service/ Product Availability \\
Calls & Network Quality \\
Payment & Billing System \\
Customer Profile & Trust / Assurance \\
Refund & Trust / Assurance \\
SIM card & Product Quality, Product Service/ Product Availability \\
SMS & Network Quality \\
Twitter & Responsiveness, Customer Support, Branch Service \\
OOT & - \\
\hline
\end{tabular}

In general, all dimensions from previous studies can be found in our identified dimensions using LDA method applied to the Twitter posts. Furthermore, by using data from social media such as Twitter, we can get a finer granularity of a dimension from previous studies. For example, a dimension from previous studies called "Product Quality" is mapped to several dimensions of our work, such as "Digital Services," "Mobile Commerce," "Basic Plan," etc. as seen in Table 4. This allows decision makers to narrow down the focus of improvements. By using data from social media, we would have a real-time data that we can analyze and provide to the decision maker, and the decision maker can create strategies based on the analysis result for the best interest of the organization. 


\section{CONCLUSION}

Our study used tweets from Twitter to identify topics/dimensions, which becomes the factor for customer satisfaction. We used PT Indosat Tbk. telecommunication services as the case study. We used the perplexity model and topic coherence to find the optimized number of topics/dimensions. Once we have the optimized number of topics/dimensions, we identify the representative words for each of the topics/dimensions. The name of the topic/dimension would then be decided manually by looking at the logical relationships between the representative words and the semantics of the words used in the original corpus. The identified names of topics/dimension are associated to the original corpus (labeling the corpus). We counted the number of the corpus with each topic to have a statistic of popular topics. Furthermore, we rationalized our identified topics/dimensions by comparing them with dimensions identified/used by previous studies. We had to broaden the definition of the dimensions from previous studies and able to find matching pairs between our identified topics/dimensions with the previous ones. This shows that the result of our method for discovering topics/dimensions of customer satisfaction agrees with previous studies.

Furthermore, our study enables dynamic discovery of customer satisfaction dimensions because the data that we used are social media data (real-time data). The benefit of using social media data is that we can get analyze this real data so that we get the current situation of the issues regarding customer satisfaction. Thus, decision-makers can decide more accurate solutions or strategy to the solution.

The limitation of our study is limited by the data we obtained from Twitter. First, Twitter has a rate limit policy, which is 15 minutes per-token, and Twitter only serves a small portion of data to be streamed. This means we are only getting a sample of data in that 15 minutes window time. Second, since tweets are temporal data, this means analysis on different time may discover different topics/dimensions. Nevertheless, this allows us to adapt to the real issues handed at that time. Thus we may react to issues that matter at that time. If the data collection is done regularly, we may analyze the data for a bigger picture and long-term strategy of the company. We may discover recurrent topics/dimensions and the ones which appear randomly or isolated on a certain period in time. To conclude our study, we have managed to used text mining techniques to discover topics from tweets data and label the topics as dimensions of customer satisfaction dimensions for telecommunication services of PT Indosat Tbk.

\section{ACKNOWLEDGEMENT}

This publication is funded by a research grant called PITTA-B number NKB-0515/UN2.R3.1/HKP.05.00/2019 provided by Universitas Indonesia. We are grateful to be funded by Universitas Indonesia. We also thank the Faculty of Computer Science, Universitas Indonesia, for supporting us in researching and publishing our work.

\section{REFERENCES}

Athanassopoulos, A. D., and Iliakopoulos, A., 2003. Modeling Customer Satisfaction In Telecommunications: Assessing The Effects Of Multiple Transaction Points On The Perceived Overall Performance Of The Provider. Production and Operations Management, pp 224-245.

Aydin, S., and Ozer, G., 2005. The analysis of antecedents of customer loyalty in the Turkish mobile telecommunication market. European Journal of Marketing, Vol. 39, No. 7/8, pp 910-925.

Buttle, F., 2009. Customer Relationship Management - Concepts and Technologies. Butterworth-Heinemann.

Gerson, R., F., 1993. Measuring Customer Satisfaction. Crisp Publication.

Khatibi, A. A., Ismail, H., and Thyagarajan, V., 2002. What drives customer loyalty: An analysis from the telecommunications industry. Journal of Targeting, Measurement and Analysis for Marketing, Vol. 11, No. 1, pp. 34-44.

Kotler, P., 2009. Marketing Management an Asian Perspective. Pearson.

Kotler, P., T., and Amstrong, G., 2017. Principles of Marketing $17^{\text {th }}$ Edition. Pearson.

Mowen, J., C., and Minor, M., 1997. Consumer Behavior Fifth Edition. Prentice Hall. 
Olatokun, W. M., and Nwonne, S. A., 2012. Determinants of Users' Choice of Mobile Service Providers in the Nigerian Telecommunications Market. African Journal of Computing \& ICT, Vol. 5, No. 4, pp19-32.

Olatokun, W. M., and Ojo, F. O., 2014. Influence of service quality on consumers' satisfaction with mobile telecommunication services in Nigeria. Information Development, Vol. 32, No. 3, pp 398-408.

Santouridis, I., and Trivellas, P., 2010. Investigating the impact of service quality and customer satisfaction on customer loyalty in mobile telephony in Greece. The TQM Journal, Vol. 22, No. 3, pp 330-343.

Wang, Y., and Lo, H.-P., 2002. Service quality, customer satisfaction and behavior intentions: Evidence from China's telecommunication industry. Info, Vol. 4, No. 6, pp 50-60. 